\title{
Estrutura Produtiva, Relações Intersetoriais e Cooperativas Agropecuárias no Paraná em 1980 e $^{1985}{ }^{1}$
}

\author{
Rossana Lott Rodrigues ${ }^{2}$ \\ Joaquim J. M. Guilhoto ${ }^{3}$
}

Resumo - Este artigo delimita e caracteriza o 'setor' cooperativa na economia do Paraná e desagrega o setor Agropecuária e os setores componentes da Indústria Alimentar das matrizes de insumo-produto, construídas para o Estado para os anos de 1980 e 1985, em Cooperativa e não-Cooperativa. O objetivo da pesquisa é caracterizar, de forma sistêmica, o perfil das relações intersetoriais, detectar os setores-chave e verificar a evolução da estrutura produtiva paranaense, destacando $\mathrm{o}(\mathrm{s})$ setor(es) relacionados às Cooperativas. A análise é realizada considerando 40 setores. As principais conclusões mostram que: os setores Celulose, Papel e Gráfica e Indústria Têxtil foram chave em 1980 e 1985, portanto, setores dinâmicos e importantes para o crescimento da economia estadual; a estrutura produtiva paranaense mostrou-se mais diversificada de 1980 para 1985, revelando conseqüente incremento da complexidade econômica; os coeficientes técnicos das cooperativas agropecuárias apresentaram-se muito similares aos das empresas nãocooperativas, evidenciando que aquelas estão acompanhando, de perto, a evolução tecnológica ocorrida nas não-cooperativas que atuam nos setores Agropecuária e na Indústria Alimentar.

\footnotetext{
${ }^{1}$ Agradecemos os comentários feitos pelos pareceristas anônimos.

${ }^{2}$ Professora da Universidade Estadual de Londrina-UEL, Departamento de Economia.

E-mail: rlott@uel.br

${ }^{3}$ Professor Titular da FEA-USP, Professor do Regional Economics Applications Laboratory (REAL), University of Illinois, e Pesquisador do CNPq. E-mail: guilhoto@usp.br
} 
Palavras-chave: análise econômica, cooperativa agropecuária, economia regional, insumo-produto, relação intersetorial.

Abstract - This paper delimits and characterizes the cooperative sector in Parana economy and breaks down the agricultural sectors and the components of food processing industries of input-output tables, built for State for the years of 1980 and 1985, in Cooperative and non-Cooperative sectors. The goal is to characterize, in systemic order, the intersectorial relations outline, detect the key- sectors and verify the evolution of the productive structure in Parana, highlighting the sectors related to Cooperatives. The analysis is made for 40 sectors. The main conclusions showed that: Paper Prod. \& Printing and Textiles sectors were key-sectors in 1980 and 1985, therefore, dynamic and important sectors for the State's economic growth; the productive structure of Parana proved to be more diversified from 1980 to 1985, showing consequent increase of economic complexity; the agricultural cooperatives technical coefficient were very similar to the non-cooperatives, showing that the first are closely following the technological evolution occurred in the non-cooperatives that act in Agricultural sector and food processing industries.

Key words - economic analysis, agricultural cooperative, regional economy, input-output, intersectorial relation.

Jel Classification: B15 e Q13

\section{1 - Introdução}

De acordo com Côté et al. (1995), as cooperativas agropecuárias não são somente a maior força socioeconômica, mas, também, um fenômeno difundido e encontrado em todos os continentes, sob todas as condições econômicas, sociais, culturais e políticas.

Apesar das desigualdades na distribuição da oferta dos alimentos e no crescimento demográfico, a demanda por alimentos tende a crescer significativamente, considerando a previsão de que a população mundial atingirá 5,7 bilhões de pessoas na virada do século e que, nos próximos 20 anos, deve crescer, aproximadamente, 1,4 bilhão (CÔTÉ et al., 1995). 
Um aspecto positivo das cooperativas agropecuárias, notadamente das que se dedicam à agroindústria, é a capacidade de dominar a cadeia produtiva de determinados produtos, o que lhes confere maior poder de concorrer de forma eficiente no mercado.

Considerando as grandes regiões do Brasil, as cooperativas do Sul destacam-se no segmento agropecuário pelo número de associados e funcionários envolvidos. São 313 cooperativas, com 468.277 associados e 65.219 funcionários, 50,7 e 57,8\% do total do segmento, respectivamente (OCB, 1997).

Na região Sul, o Estado do Paraná é o que apresenta o cooperativismo mais organizado e, nele, o segmento agropecuário é o mais desenvolvido. Em 1996, eram 66 cooperativas e 119.756 associados, dos quais $75 \%$ trabalhavam em módulos de área de até 50 ha (OCEPAR, 1997a).

Estudar a importância dos setores agropecuária e componentes da indústria alimentar ligados às cooperativas na economia paranaense é importante por várias razões. Uma delas refere-se ao fato de que, na primeira metade dos anos 80 , as cooperativas constituíram-se em importante instrumento de política pública, participando da disseminação de tecnologias e da implementação de políticas desenvolvimentistas do governo. No Paraná, isso ocorreu com a difusão do crédito rural, da armazenagem, manejo e conservação de solos, manejo integrado de pragas, assentamento de agricultores, viabilização da comercialização, com os programas PRORURAL e Paraná Rural, etc. (OCEPAR, 1997b)³.

Outra razão que conduziu à realização deste estudo foi o papel desempenhado pelas cooperativas na organização da produção, permitindo, via integração dos produtores, redução dos agentes de comercialização e aumento da eficiência dos mecanismos de arrecadação tributária do Estado. Essa ação faz das cooperativas importantes instrumentos, também, na execução da política fiscal do governo.

Dentro desse contexto, torna-se relevante levantar as seguintes questões: como evoluiu a estrutura produtiva do Paraná de 1980 para 1985?;

\footnotetext{
${ }^{3}$ O Programa de Apoio ao Pequeno Produtor Rural (PRORURAL) e o Paraná Rural, ambos extintos atualmente, foram programas de âmbito estadual, implantados na década de 80 , que tinham como objetivo geral auxiliar o pequeno produtor no desenvolvimento de suas atividades, de modo a proporcionar-lhe condições para melhoria do nível de vida e de renda [TURRA, F. E. (OCEPAR, Curitiba). Comunicação pessoal, 2000].
} 
qual o poder de encadeamento dos diversos setores econômicos do Estado?; quais as características das relações intersetoriais das cooperativas com os demais setores da economia?; as cooperativas agropecuárias constituem setor-chave na economia estadual?

Para responder a essas questões propõe-se o emprego da análise insumo-produto, pois é o instrumental analítico mais adequado para identificar, de forma sistêmica, a interdependência setorial, bem como orientar nas políticas econômicas que podem ser implementadas no sentido de permitir maior participação das cooperativas agropecuárias na economia estadual.

Um esclarecimento deve ser feito com relação ao período estudado. Embora passados 19 anos, a análise aqui proposta só foi possível depois que foram estimadas as matrizes de insumo-produto para o Paraná, a partir de 1980. Considerando que a comparação entre a estrutura produtiva estadual dos anos 80 (inserida numa economia nacional fechada) com a dos anos 90 (relativa à economia brasileira aberta e integrada via MERCOSUL) possa revelar alterações e tendências importantes no que se refere à conformação/arranjo dos setores e às relações intersetoriais no Estado, este artigo confirma algumas mudanças que estão sendo delineadas dentro da nova e atual realidade econômica estadual, nacional e mundial.

Finalmente, em que pesem as diferenças entre as empresas cooperativas e as não-cooperativas relatadas na seção abaixo e, por isso, a expectativa de que haja diversidade na performance tecnológica de ambas, a hipótese do presente trabalho é de que, em termos de coeficientes técnicos, não há grandes diferenças entre elas uma vez que as duas são empresas que concorrem entre si no mesmo mercado ${ }^{4}$. Do contrário, o próprio mercado se encarregaria de excluir as de pior desempenho. Assim, as cooperativas e as não-cooperativas que permaneceram ativas nos anos 80 devem ter apresentado coeficientes técnicos bastante semelhantes.

\footnotetext{
${ }^{4}$ É grande a profusão de trabalhos que analisam a cooperativa como empresa, notadamente nos países da Europa e nos Estados Unidos. No Brasil, dentre as várias investigações pode-se citar Bialoskorski Neto e Zylbersztajn (1994), Zylbersztajn (1994) e Bialoskorski Neto (1998).
} 


\section{2 - As cooperativas enquanto setor de produção ${ }^{5}$}

\section{1 - Empresa cooperativa e empresa não-cooperativa}

Vários estudos sobre cooperativas mencionam, com maior ou menor grau de detalhamento, as diferenças entre essas empresas e as nãocooperativas.

Segundo Gonçalves e Vergo (1994), do ponto de vista jurídico, as duas conformações básicas que as empresas que dominam o núcleo da cadeia produção-consumo da agropecuária podem assumir, são: a sociedade por ações e a sociedade por quotas.

A empresa não-cooperativa é uma sociedade por ações. Quem detém maior participação no capital, detém, também, maior poder de decisão. Por outro lado, a empresa cooperativa é uma sociedade por quotas, centrada no princípio de um homem/um voto no processo de tomada de decisões.

Em resumo, pode-se dizer que a diferença básica entre cooperativa e não-cooperativa é a organização do capital, uma vez que ela será a grande responsável pela forma com que se tomarão as decisões relativas às estratégias empresariais.

\section{2 - O 'setor' cooperativa}

A definição mais simples para "setor de atividade", que aparece nos livros clássicos de microeconomia, é "um conjunto de firmas produzindo um bem homogêneo" (FERGUSON, 1982). O 'setor de atividade' é utilizado quando se faz referência à concorrência perfeita ou ao monopólio. No caso da diferenciação do produto ser fator importante do mercado, pode-se agregar firmas produtoras de bens proximamente relacionados e referir-se a elas como um "grupo de produção" (FERGUSON, 1982).

\footnotetext{
${ }^{5}$ Os termos setor e indústria serão usados indistintamente neste artigo, considerando que se fará uso da análise de insumo-produto para a qual essas denominações são, geralmente, usadas como sinônimos, segundo Miller e Blair (1985).
} 
Na análise insumo-produto, uma das hipóteses adotadas é a de que o número de setores ou indústrias é igual ao número de bens produzidos. Em outras palavras, cada setor ou indústria produz um único bem. Diante disso, a definição clássica de 'setor de atividade' mencionada acima será adotada neste estudo, considerando que, dado seu nível de agregação, a distinção precisa não é importante para os propósitos do trabalho.

A conjugação do conceito de 'setor de atividade' com as características específicas das cooperativas salientadas anteriormente, permite delimitar o 'setor' cooperativa na economia paranaense e remeter ao uso do instrumental insumo-produto como o mais indicado para detectar, de forma sistêmica, as relações setoriais presentes na economia do Estado, com destaque para o 'setor' cooperativa.

\section{3 - Metodologia}

Partindo das relações fundamentais da análise de insumo-produto, descritas em Miller e Blair (1985), e utilizando o método do quociente locacional, classificado por Haddad et. al. (1989) como medida de localização, Rodrigues (2000) estimou as matrizes de insumo-produto para o Paraná para os anos de 1980 e 1985, estruturadas em 40 setores .

A partir das matrizes regionais, foram usados os seguintes métodos de análise para atingir os objetivos propostos: índices de ligações de Rasmussen-Hirschman, campo de influência e matriz de intensidade.

Os índices de ligações de Rasmussen-Hirschman, ao considerarem a estrutura interna da economia baseada no modelo de insumo-produto, determinam os setores que teriam o maior poder de encadeamento dentro da economia, isto é, as ligações para trás, que estimam o quanto um setor demanda dos outros setores, e para frente, que informam o quanto um setor é demandado pelos outros [RASMUSSEN (1956), HIRSCHMAN (1958) e GUILHOTO et al. (1994)].

Desse modo, com base na equação $L=(I-A)^{-1}$, em que $I$ é a matriz identidade e $A=|a i j|$ é a matriz de coeficientes técnicos de produção, define-se $l_{i j}$ como um elemento da matriz inversa de Leontief, $L, L^{*}$ como a média de todos os elementos de $L$ e $L_{\bullet j}$ e $L_{i \bullet}$ como a soma dos elementos 
de uma coluna e de uma linha típica de $L$, dada, respectivamente, como

$$
L_{\bullet j}=\sum_{i=1}^{n} l_{i j} \quad \text { e } \quad L_{i \bullet}=\sum_{j=1}^{n} l_{i j} \quad \mathrm{i}, \mathrm{j}=1,2, \ldots \mathrm{n}
$$

Assim:

índices de ligações para trás:

$$
U_{j}=\left[L_{\bullet j} / n\right] / L^{*}
$$

índices de ligações para frente:

$$
U_{i}=\left[L_{i \bullet} / n\right] / L^{*}
$$

Para Rasmussen e Hirschman, valores maiores do que 1, tanto dos índices de ligações para trás quanto para frente, indicam setores acima da média e, portanto, setores-chave para o crescimento da economia.

Apesar dos índices de ligações de Rasmussen-Hirschman avaliarem a importância dos setores em termos de seus impactos no sistema como um todo, dificultam a visualização dos principais elos de ligações dentro da economia, isto é, de quais seriam os coeficientes que, se alterados, teriam um maior impacto no sistema como um todo. Visando superar este problema, utiliza-se o enfoque do campo de influência desenvolvido por Sonis e Hewings (1989 e 1994).

O conceito de campo de influência descreve como se distribuem as mudanças dos coeficientes diretos no sistema econômico como um todo, permitindo, assim, determinar quais as relações entre os setores que seriam mais importantes dentro do processo produtivo. Desse modo, o conceito de campo de influência se apresenta como uma análise complementar à dos índices de ligações de Rasmussen-Hirschman, uma vez que os principais elos de ligação dentro da economia vão ocorrer nos setores que apresentam os maiores índices de ligações, tanto para frente como para trás.

O procedimento para o cálculo do campo de influência requer a matriz A e uma matriz de variações incrementais nos coeficientes diretos de insumo, $E=\left|\varepsilon_{i j}\right|$. As correspondentes matrizes inversas de Leontief são dadas por $L=[I-A]^{-1}=\left|l_{i j}\right|$ e por $L(\varepsilon)=[I-(A+\varepsilon)]^{-1}=\left|l_{j i}(\varepsilon)\right|$. De 
acordo com Sonis e Hewings (1989 e 1994), caso a variação seja pequena e só ocorra num coeficiente direto, isto é:

$$
\varepsilon_{i j}=\left\{\begin{array}{c}
\varepsilon \quad i=i_{1}, j=j_{1} \\
0 \quad i \neq i_{1} \text { ou } j \neq j_{1}
\end{array}\right.
$$

o campo de influência desta variação pode ser aproximado pela expressão:

$$
F\left(\varepsilon_{i j}\right)=\frac{\left\lfloor L\left(\varepsilon_{i j}\right)-L\right\rfloor}{\varepsilon_{i j}}
$$

em que $F\left(\varepsilon_{i j}\right)$ é a matriz $(n \times n)$ do campo de influência do coeficiente $a_{i j}$.

Para determinar quais os coeficientes que possuem o maior campo de influência, associa-se a cada matriz $F\left(\varepsilon_{i j}\right)$ um valor que é dado por:

$$
S_{i j}=\sum_{k=l}^{n} \sum_{l=1}^{n}\left[f_{k l}\left(\varepsilon_{i j}\right)\right]^{2}
$$

Desse modo, os coeficientes diretos que possuem os maiores valores de $S_{i j}$ serão aqueles com maior campo de influência dentro da economia como um todo.

Recentemente, Sonis et al. (1997) e Sonis e Hewings (1999) expandiram a técnica do campo de influencia para introduzir a noção de intensidade, a qual pode ser visualizada por meio de matriz tridimensional.

Nesta abordagem, deriva-se a matriz do produto dos multiplicadores (MPM) que revela a hierarquia das ligações para trás e para frente, delineando a topografia econômica a ela relacionada e refletindo a estrutura de cruz associada à MPM.

Mais especificamente, a MPM pode ser derivada a partir dos multiplicadores das linhas e das colunas da matriz inversa de Leontief apresentados anteriormente. Assim, os vetores linha e coluna dos multiplicadores coluna e linha podem ser apresentados, respectivamente, como:

$$
M_{c}(L)=\left[\begin{array}{llll}
L_{\bullet 1} & L_{\bullet 2} & \ldots & L_{\bullet n}
\end{array}\right] \quad \text { e } \quad M_{l}(L)=\left(\begin{array}{c}
L_{1 \bullet} \\
L_{2 \bullet} \\
\ldots \\
L_{n \bullet}
\end{array}\right)
$$


Admitindo que $l_{\text {.. }}$ seja a soma de todos os elementos da matriz inversa de Leontief, denominada de intensidade global da matriz, dada por:

$$
l_{. .}=\sum_{i=1}^{n} \sum_{j=1}^{n} l_{i j}
$$

define-se a matriz de intensidade ou a MPM como:

$$
M=\frac{1}{l_{\bullet \bullet}}\left\|L_{i \bullet} L_{\bullet j}\right\|=\frac{1}{l_{\bullet \bullet}}\left(\begin{array}{c}
L_{1 \bullet} \\
L_{2} \\
\ldots \\
L_{n \bullet}
\end{array}\right)\left(\begin{array}{llll}
L_{\bullet 1} & L_{\bullet 2} & \ldots & L_{\bullet n}
\end{array}\right)=\left\|m_{i j}\right\|
$$

A organização das linhas e colunas de M pode ser feita de modo que os centros dos cruzamentos correspondentes apareçam na diagonal principal. Neste caso, a matriz M mostrará uma topografia econômica descendente, baseada na seqüência de ordenação por tamanho dos multiplicadores coluna e linha.

Este arranjo, também, revela a hierarquia descendente dos índices para frente e para trás de Rasmussen-Hirschmam [SONIS et al. (1997) e SONIS e HEWINGS (1999)]. Contudo, a construção da matriz M é importante pois permite explorar, de forma consistente e complementar, a estrutura destes índices tradicionais.

A matriz $\mathrm{M}$ pode ser construída para diferentes regiões ou para a mesma região em diferentes pontos no tempo, o que cria a possibilidade de estabelecer uma classificação sistemática destas economias.

Desse modo, adotando como numeraire ou base a ordenação por tamanho dos multiplicadores coluna e linha de certa economia ou de dado período, a topografia econômica pode ser visualmente comparada: desvios da topografia descendente retratada pela economia tomada como base, refletirão diferenças na estrutura econômica entre as regiões ou entre períodos distintos em uma mesma região. Estas diferenças mostrarão, no caso de estudos com mais de uma região, variação no conjunto de indústrias das regiões, variação no grau da intermediação 
intraregional e variação na tecnologia. Considerando uma região em pontos diferentes no tempo, as alterações poderão refletir variação no mix de indústrias, variações no grau de ligações setoriais, bem como mudanças na tecnologia ocorridas nesta economia.

A topografia econômica resultante da MPM, embora não substitua outras técnicas, constitui em ferramenta complementar na definição preliminar de diferenças e similaridades entre economias ou entre diferentes períodos da mesma economia.

\section{4 - Resultados}

\section{1 - Evolução da participação setorial no valor adicionado e no valor da produção}

Visando dimensionar a participação dos setores na economia estadual, serão usados o valor adicionado (va) e o valor da produção (vp) mostrados na Tabela 1 . 
Tabela 1 - Participação setorial no valor adicionado (va) e no valor da produção (vp) do Paraná, 1980 e 1985.

(Em \%)

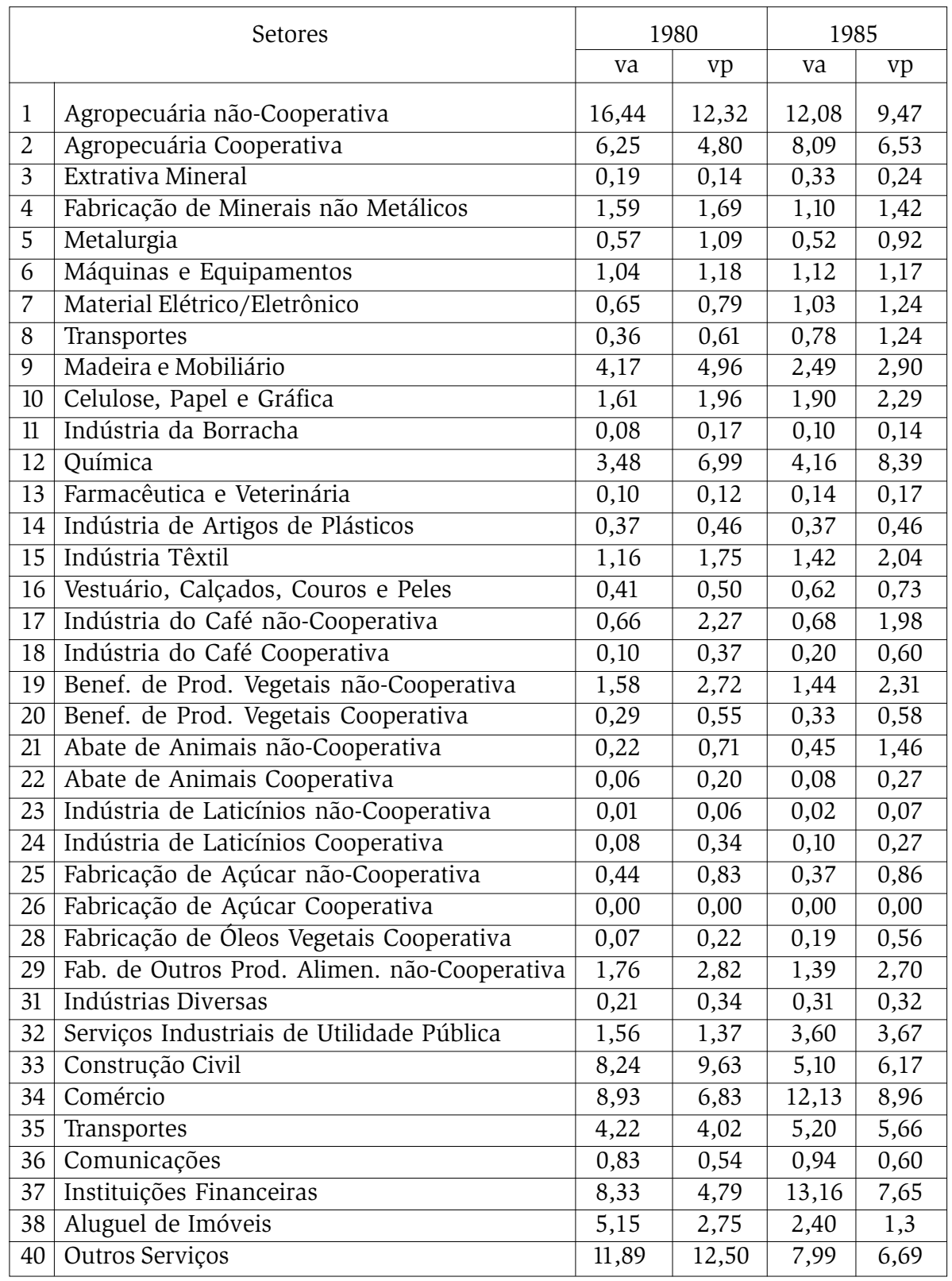

Fonte: dados da pesquisa. 
Observa-se que os setores Agropecuária (1 e 2) apresentam, juntos, a maior participação no va e no vp durante todo o período estudado. As posições seguintes são alternadas entre os setores do ramo serviços (32 a 40), que apresentam crescimento da participação no va e no vp, reforçando a já conhecida tendência histórica registrada com o desenvolvimento das economias. Dentre esses setores, cabe destacar, nos anos de 1980 e 1985, os setores Comércio (34) e Instituições Financeiras (37) (Tabela 1).

Os setores componentes da indústria de transformação (4 a 31) apresentaram, de forma geral, crescimento da participação no va e no vp nos anos de 1980 e 1985. Entretanto, alguns comentários merecem ser feitos relativamente à indústria de transformação. A indústria alimentar (setores 17 a 30), permaneceu como importante segmento da economia paranaense em 1980 e 1985, detendo cerca de 6,3\% e 14,3\%, em média, da participação no va e no vp, respectivamente, participações que lhe conferiu o primeiro lugar no segmento industrial.

O setor Química (12) apresentou crescimento importante da participação no va e no vp entre 1980 e 1985, resultado da implantação de uma unidade da PETROBRAS em Araucária, na região metropolitana de Curitiba.

A Tabela 1 mostra, também, que, dos setores estudados, oito estão desagregados em cooperativa e não-cooperativa. Esses setores são aqueles nos quais as cooperativas agropecuárias paranaenses têm atuado mais tradicionalmente na produção de alimentos in natura e processados. Assim, são relacionados dois setores produtores de alimentos in natura, (1) e (2), e 14 setores produtores de alimentos processados ou componentes da indústria alimentar, (17), (18), (19), (20), (21), (22), (23), (24), (25), (26), (27), (28), (29) e (30).

Considerando que um dos objetivos do presente estudo é analisar o setor Cooperativa, é traçado um cenário evolutivo do período 1980/85, com base no valor adicionado (va) e no valor da produção (vp) setorial. Este cenário balizará a análise relativa às ligações setoriais e setoreschave na economia paranaense.

Antes, porém, é interessante fazer uma rápida referência aos anos que antecedem o período estudado, de forma a caracterizar a conjuntura da época, que, certamente, influenciou no comportamento e nas decisões dos agentes econômicos no futuro próximo. 
Na década de 70, as cooperativas paranaenses apresentaram crescimento intenso, reflexo de um conjunto de fatores favoráveis. Dentre eles poderiam ser citados: 1) o destaque dado ao setor cooperativo, pelo Estado, na modernização agrícola, concedendo-lhe posição privilegiada como agentes da Comissão de Organização da Triticultura Nacional (COTRIN) ${ }^{6}$; 2) as mudanças na legislação cooperativista, especialmente a Lei 5.764, de 16/12/71, permitindo às cooperativas maior flexibilidade de atuação como empresas comerciais; 3) a posição das cooperativas como agentes da Comissão de Financiamento da Produção (CFP) na execução da política de preços mínimos e, fundamentalmente 4) o acesso dessas empresas a créditos oficiais altamente subsidiados para aumento de sua capacidade instalada e diversificação de suas atividades (IPARDES, 1985).

No período 1975/83, a indústria alimentar paranaense pôde ser caracterizada como diversificada e integrada a mercados externos ao Estado, detentora de parque industrial recente, com nítida tendência à concentração econômica e conseqüente predomínio de grandes estabelecimentos. Nesses anos, registrou-se, também, o aumento da presença das cooperativas na indústria alimentar do Paraná.

Entre 1980 e 1985, os setores produtores de alimentos processados ligados às cooperativas $(18,20,22,24,26,28$, e 30$)$ elevaram sua participação no va e no vp da indústria alimentar do Estado de 10,43\% para $16,48 \%$ e de $12,46 \%$ para $17,41 \%$, respectivamente. Em contrapartida, os setores não-cooperativos $(17,19,21,23,25,27$ e 29) reduziram sua participação no va e no vp da indústria alimentar de $89,57 \%$ para $83,52 \%$ e de $87,44 \%$ para $82,59 \%$ (Tabela 1 ).

A expansão da participação das cooperativas foi marcante tanto nos setores de atuação tradicional, como Beneficiamento de Produtos Vegetais (20), Fabricação de Outros Produtos Alimentares (30), quanto em áreas nas quais as cooperativas iniciaram posteriormente suas atividades, como Fabricação de Óleos Vegetais (28) e Abate de Animais (22).

É interessante destacar dois aspectos que caracterizaram o caminho das cooperativas para a verticalização. O primeiro é a constatação de que as cooperativas decidiram-se, claramente, pela instalação de unida-

\footnotetext{
${ }^{6}$ Esta Comissão foi criada em 1955, com o objetivo de organizar e desenvolver a triticultura no Brasil.
} 
des industriais de porte relativamente grande, a exemplo das empresas não-cooperativas atuantes na indústria alimentar. $\mathrm{O}$ segundo se refere ao fato de que a mobilização de capital próprio não foi a principal fonte de financiamento da industrialização inicial destas empresas, como também não foi das inversões privadas (IPARDES, 1985).

A prévia e sólida inserção das cooperativas na comercialização de produtos agrícolas é apontada como um dos fatores que teriam contribuído para que essas empresas ampliassem o peso de sua presença na indústria alimentar (IPARDES, 1985).

Quanto à agropecuária, é interessante observar que o setor Agropecuária Cooperativa, diferentemente do setor Agropecuária nãoCooperativa (2), elevou sua participação tanto no va quanto no vp nos anos de 1980 e 1985 (Tabela 1).

\section{2 - Ligações industriais e setores-chave na economia do Paraná}

\subsection{1 - Os índices de Rasmussen-Hirschman}

A Tabela 2 mostra os resultados dos índices de ligações de RasmussenHirschman para os anos e setores estudados, bem como a ordem de importância dos mesmos na economia.

Uma visão panorâmica da Tabela 2 permite destacar somente dois setores-chave para o crescimento da economia paranaense, levando em conta o conceito restrito (ambos os índices maiores do que 1): Celulose, Papel e Gráfica (10) e Indústria Têxtil (15), ambos componentes da indústria de transformação. Levando em conta somente o ano de 1980, além dos dois setores acima mencionados, o setor Fabricação de Outros Produtos Alimentares não-Cooperativa (29) também foi chave na economia estadual (Tabela 2). Entretanto, a evolução do perfil da estrutura produtiva paranaense pode ser melhor caracterizada considerando a definição menos restrita de setores-chave (um dos índices maior do que 1). Dentro dessa perspectiva, o Paraná apresentou, além dos setores assinalados anteriormente, 21 setores-chave em 1980 (14 com ligações para trás e 7 com ligações para frente), 23 em 1985 (16 com ligações para trás e 7 com ligações para frente).

Essas informações evidenciaram as seguintes características da eco- 
Tabela 2 - Índices de Rasmussen-Hirschman, Paraná, 1980 e 1985.

\begin{tabular}{|c|c|c|c|c|c|c|c|c|}
\hline \multirow[t]{2}{*}{ Setores } & \multicolumn{4}{|c|}{1980} & \multicolumn{4}{|c|}{1985} \\
\hline & Trás & Ordem & Frente & Ordem & Trás & Ordem & Frente & Ordem \\
\hline 1 Agropecuária não-Cooperativa & 0,8744 & 25 & 4,0292 & 1 & 0,8773 & 26 & 3,6184 & 2 \\
\hline 2 Agropecuária Cooperativa & 0,8999 & 24 & 1,7899 & 4 & 0,9125 & 22 & 2,1254 & 3 \\
\hline 3 Extrativa Mineral & 0,7858 & 32 & 0,5927 & 33 & 0,7398 & 36 & 0,6627 & 27 \\
\hline 4 Fabricação de Minerais não Metálicos & 0,9523 & 19 & 0,8791 & 13 & 1,0135 & 18 & 0,9327 & 11 \\
\hline 5 Metalurgia & 0,7857 & 33 & 0,7556 & 19 & 0,7739 & 34 & 0,7207 & 20 \\
\hline 6 Máquinas e Equipamentos & 0,7730 & 35 & 0,7763 & 18 & 0,7517 & 35 & 0,7934 & 17 \\
\hline 7 Material Elétrico/Eletrônico & 0,7918 & 29 & 0,6248 & 25 & 0,7993 & 32 & 0,6866 & 25 \\
\hline 8 Material de Transporte & 0,7765 & 34 & 0,6083 & 30 & 0,8003 & 31 & 0,6985 & 22 \\
\hline 9 Madeira e Mobiliário & 1,0606 & 14 & 0,8191 & 15 & 1,0198 & 17 & 0,7757 & 18 \\
\hline 10 Celulose, Papel e Gráfica & 1,0770 & 13 & 1,2147 & 7 & 1,0622 & 14 & 1,2509 & 7 \\
\hline 11 Indústria da Borracha & 0,9395 & 21 & 0,6266 & 23 & 0,8708 & 27 & 0,6180 & 34 \\
\hline 12 Química & 0,8423 & 27 & 3,3024 & 2 & 0,8957 & 24 & 3,7083 & 1 \\
\hline 13 Farmacêutica e Veterinária & 0,9486 & 20 & 0,5593 & 38 & 0,9727 & 21 & 0,5746 & 39 \\
\hline 14 Indústria de Artigos de Plásticos & 1,0134 & 16 & 0,7111 & 22 & 1,0433 & 16 & 0,7201 & 21 \\
\hline 15 Indústria Têxtil & 1,0604 & 15 & 1,0777 & 8 & 1,1025 & 13 & 1,1810 & 9 \\
\hline 16 Vestuário, Calçados, Couros e Peles & 0,9687 & 18 & 0,5646 & 37 & 0,9880 & 19 & 0,5868 & 37 \\
\hline 17 Indústria do Café não-Cooperativa & 1,5782 & 2 & 0,9883 & 11 & 1,3958 & 2 & 0,7990 & 16 \\
\hline 18 Indústria do Café Cooperativa & 1,5885 & 1 & 0,6173 & 29 & 1,4083 & 1 & 0,6330 & 32 \\
\hline 19 Benef. de Prod. Vegetais não-Cooperativa & 1,1400 & 12 & 0,7805 & 16 & 1,0593 & 15 & 0,8184 & 15 \\
\hline 20 Benef. de Prod. Vegetais Cooperativa & 1,1604 & 10 & 0,5935 & 32 & 1,1128 & 12 & 0,6247 & 33 \\
\hline 21 Abate de Animais não-Cooperativa & 1,2795 & 6 & 0,6229 & 26 & 1,3160 & 6 & 0,6985 & 23 \\
\hline 22 Abate de Animais Cooperativa & 1,2835 & 5 & 0,5673 & 36 & 1,3208 & 4 & 0,5855 & 38 \\
\hline 23 Indústria de Laticínios não-Cooperativa & 1,2753 & 7 & 0,5780 & 34 & 1,1930 & 10 & 0,5926 & 35 \\
\hline 24 Indústria de Laticínios Cooperativa & 1,2676 & 8 & 0,7175 & 21 & 1,1964 & 9 & 0,6906 & 24 \\
\hline 25 Fab. de Açúcar não-Cooperativa & 1,0073 & 17 & 0,7770 & 17 & 1,1468 & 11 & 0,8194 & 14 \\
\hline 26 Fab. de Açúcar Cooperativa & - & - & - & - & - & - & - & - \\
\hline 27 Fab. de Óleos Vegetais não-Cooperativa & 1,2851 & 4 & 0,9278 & 12 & 1,3207 & 5 & 0,9806 & 10 \\
\hline 28 Fab. de Óleos Vegetais Cooperativa & 1,2949 & 3 & 0,5769 & 35 & 1,3325 & 3 & 0,6453 & 28 \\
\hline $\begin{array}{l}29 \text { Fab. de Outros Prod. Alimentares } \\
\text { não-Cooperativa }\end{array}$ & 1,1588 & 11 & 1,0441 & 9 & 1,2237 & 8 & 0,8219 & 13 \\
\hline $\begin{array}{l}30 \text { Fab. de Outros Prod. Alimentares } \\
\text { Cooperativa }\end{array}$ & 1,1829 & 9 & 0,5571 & 39 & 1,2450 & 7 & 0,5879 & 36 \\
\hline 31 Indústrias Diversas & 0,8101 & 28 & 0,6213 & 27 & 0,8488 & 28 & 0,6355 & 30 \\
\hline 32 Serv. Ind. de Utilidade Pública & 0,8688 & 26 & 1,0201 & 10 & 0,9814 & 20 & 1,2388 & 8 \\
\hline 33 Construção Civil & 0,9123 & 23 & 0,7228 & 20 & 0,8978 & 23 & 0,7289 & 19 \\
\hline 34 Comércio & 0,7905 & 30 & 1,4243 & 5 & 0,8059 & 30 & 1,8305 & 4 \\
\hline 35 Transporte & 0,7893 & 31 & 1,3066 & 6 & 0,8827 & 25 & 1,5134 & 5 \\
\hline 36 Comunicações & 0,7216 & 37 & 0,6210 & 28 & 0,6990 & 37 & 0,6692 & 26 \\
\hline 37 Instituições Financeiras & 0,6939 & 38 & 0,8205 & 14 & 0,6714 & 39 & 0,8257 & 12 \\
\hline 38 Aluguel de Imóveis & 0,6741 & 39 & 0,6258 & 24 & 0,6790 & 38 & 0,6345 & 31 \\
\hline 39 Administração Pública & 0,7623 & 36 & 0,6061 & 31 & 0,7987 & 33 & 0,6365 & 29 \\
\hline 40 Outros Serviços & 0,9253 & 22 & 2,9519 & 3 & 0,8409 & 29 & 1,3359 & 6 \\
\hline
\end{tabular}

Fonte: dados da pesquisa. 
nomia paranaense nesses anos: a) a conjugação de índices de ligações para trás elevados em todos os setores alimentares (17 a 30), com índices de ligações para frente mais elevados nos setores Agropecuária (1 e 2), Serviços (32, 34, 35 e 40) e Química (12), permite afirmar que o Paraná apresentava, nos anos 80, indústria pouco diversificada, centrada nas indústrias produtoras de alimentos e na agropecuária enquanto fornecedora de matérias-primas; b) o número de setores com ligações para trás foi, praticamente, o dobro do número de setores com ligações para frente, evidenciando que são aceitáveis políticas que objetivem estimular a demanda por insumos intermediários, notadamente se essa demanda for atendida por insumos domésticos; c) o comportamento dos índices de ligações para trás dos setores alimentares aponta na direção de queda da importância dos mais tradicionais, como Indústria do Café (17 e 18) e Beneficiamento de Produtos Vegetais (19 e 20), enquanto setores indutores do crescimento da economia estadual; d) por outro lado, os setores alimentares mais modernos, ou com novas atividades, registraram menor decréscimo, a exemplo da Indústria de Laticínios (23 e 24), ou mesmo crescimento no seu dinamismo, como foi o caso de Abate de Animais (21 e 22), Fabricação de Óleos Vegetais (27 e 28) e Fabricação de Outros Produtos Alimentares (29 e 30); e) outros setores da indústria de transformação, tais como Fabricação de Minerais não Metálicos (4) e Material de Transporte (8) e, em menor grau, Material Elétrico/Eletrônico (7) parecem emergir na economia paranaense, delineando tendência futura de maior diversificação industrial; f) os setores do ramo serviços ganham importância para o crescimento da economia estadual.

O tamanho dos índices de ligações é um indicador da capacidade dos setores em dinamizar a economia. Com base na Tabela 2, e considerando os quatro maiores índices de ligações para frente, observa-se que a oferta de insumos se processou pelos setores Agropecuária não-Cooperativa (1), Agropecuária Cooperativa (2), Química (12) e Outros Serviços (40) em 1980. Em 1985 essa combinação alterou-se pouco, com a substituição do setor (40) pelo setor Comércio (34).

Por outro lado, levando em conta os quatro maiores índices de ligações para trás, três deles foram relativos a setores vinculados às cooperativas, Indústria de Café (18), Abate de Animais (22) e Fabricação de Óleos vegetais (28), e um à Indústria de Laticínios não-Cooperativa (23) 
em 1980. Já em 1985, os setores (18), (22), (24) e (28), concentraram a demanda por insumos para o processamento industrial no Paraná.

\subsection{2 - O Campo de Influência}

Para complementar a análise dos índices de ligações de RasmussenHirschman e detectar como se distribuem as alterações dos coeficientes diretos no sistema econômico como um todo, foi calculado o campo de influência. Assim, as relações intersetoriais mais importantes dentro do processo produtivo da economia paranaense nos anos em tela podem ser vistas nas Figuras 1 e 2, onde são apresentados os 50 coeficientes setoriais com maior campo de influência.

Em 1980, se pequenas mudanças nos coeficientes diretos de produção ocorressem na economia estadual, as relações comerciais da Indústria do Café não-Cooperativa (17) seriam as grandes propagadoras dessas alterações no sistema, apresentando sete coeficientes relativos à venda e um envolvendo compras. Certamente, a importância desempenhada pelo café na economia paranaense na década de 80 pode ser vista como principal razão desse comportamento (Figura 1).

Dentro desse contexto, e considerando somente o lado das compras, cabe destacar, em primeiro lugar, o setor Agropecuária não-Coo-

Figura 1 - Coeficientes setoriais com maior campo de influência, Paraná, 1980.

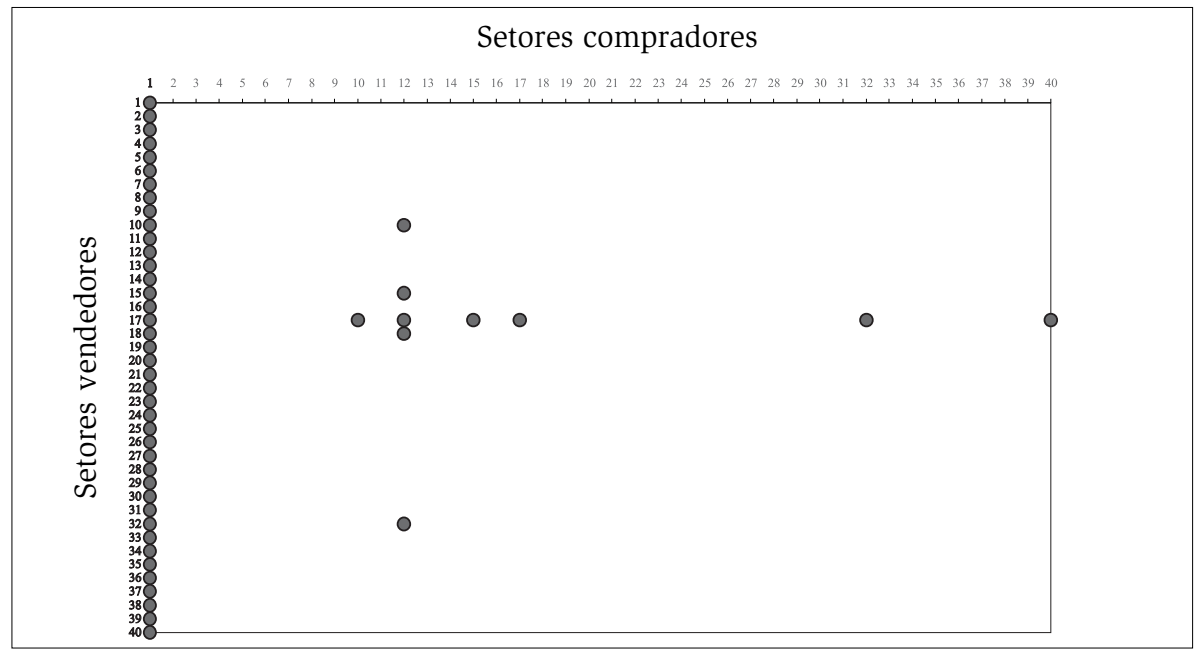


perativa (1), comprando de todos os setores, e o setor Química (12), com compras dos setores (10), (15), (17), (18) e (32).

A Figura 2 revela que, em 1985, os principais elos de ligações da economia são dominados pelos setores Têxtil (15) e Serviços Industriais de Utilidade Pública (32), ambos com quatro coeficientes relativos a vendas para outros setores e quatro envolvendo compras de seus produtos.

Novamente, para os setores Agropecuária não-Cooperativa (1) e Química (12) a dominância se apresentou mais relacionada às ligações para trás, com 28 dos 50 coeficientes com maior campo de influência localizados no primeiro e 14 no segundo, confirmando a importância destes setores como principais compradores de insumos dos demais setores da economia diante de alterações nos seus coeficientes diretos.

No ano de 1985, emergem setores que apresentam ligações importantes somente na direção das vendas, como Celulose, Papel e Gráfica (10), Têxtil (15) e Serviços Industriais de Utilidade Pública (32) (Figura 2).

Nos anos analisados, algumas tendências importantes puderam ser detectadas: a) a economia paranaense apresentou-se mais interligada, com maior número de relações intersetoriais importantes dentro do

Figura 2 - Coeficientes setoriais com maior campo de influência, Paraná, 1985

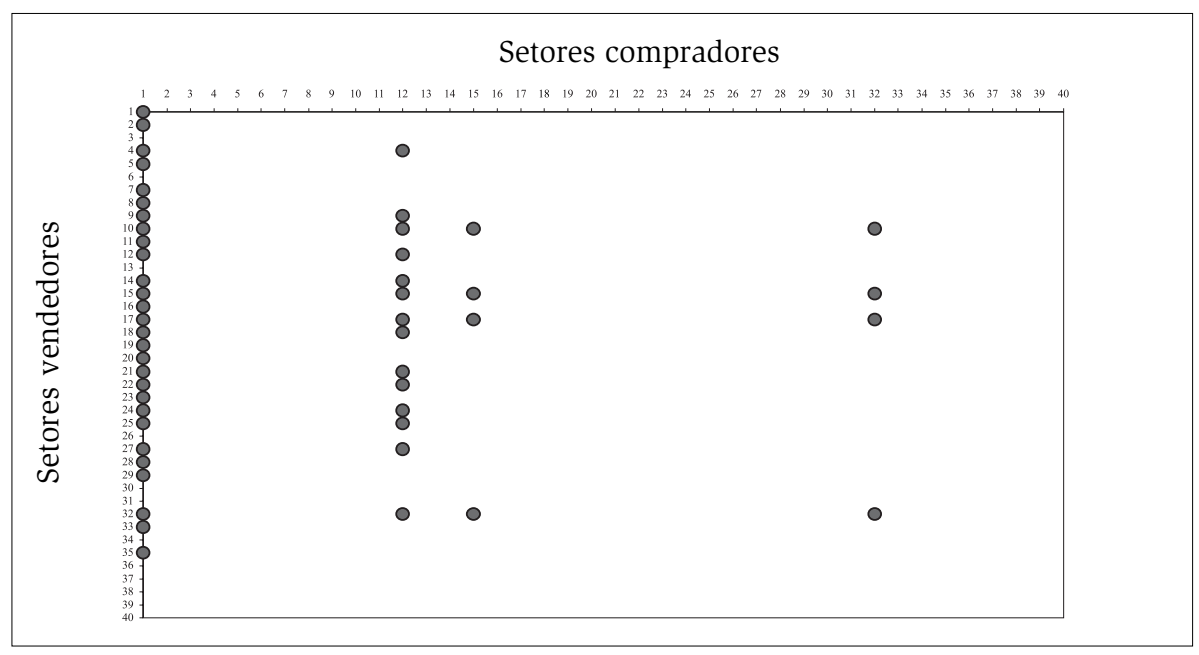


processo produtivo; b) essa diversificação ocorreu com maior intensidade no segmento de transformação; c) o setor Agropecuária não-Cooperativa continuou sendo o mais importante comprador de insumos na economia estadual, embora tenha cedido espaço para outros setores; d) as relações de comércio envolvendo os setores (1), (12), (15) e (32) nos anos de 1980 e 1985 tiveram profundo efeito no resto da economia.

\section{3 - Estrutura de Produção Paranaense: a 'topografia' econômica}

A estrutura produtiva da economia do Paraná para os dois anos estudados está retratada nas Figuras 3 e 4. Nelas, pode-se visualizar a 'topografia' setorial da economia do Estado, tomando as medidas de intensidade de 1980 como base.

Observou-se que, no ano de 1980, o pico da hierarquia ocorreu na interseção do setor Agropecuária não-Cooperativa (1) e Indústria do Café Cooperativa (18), seguido pelo setor Agropecuária não-Cooperativa (1) e Indústria do Café não-Cooperativa (17). Os setores Agropecuária nãoCooperativa (1) e Química (12), seguidos do setor Outros Serviços (40) são, visivelmente, os que apresentaram, com a Indústria do Café Cooperativa (18), as combinações com maiores picos em 1980. A partir do quarto cruzamento, os picos decresceram de forma mais homogênea (Figura 3).

Figura 3 - Topografia da estrutura econômica do Paraná, 1980

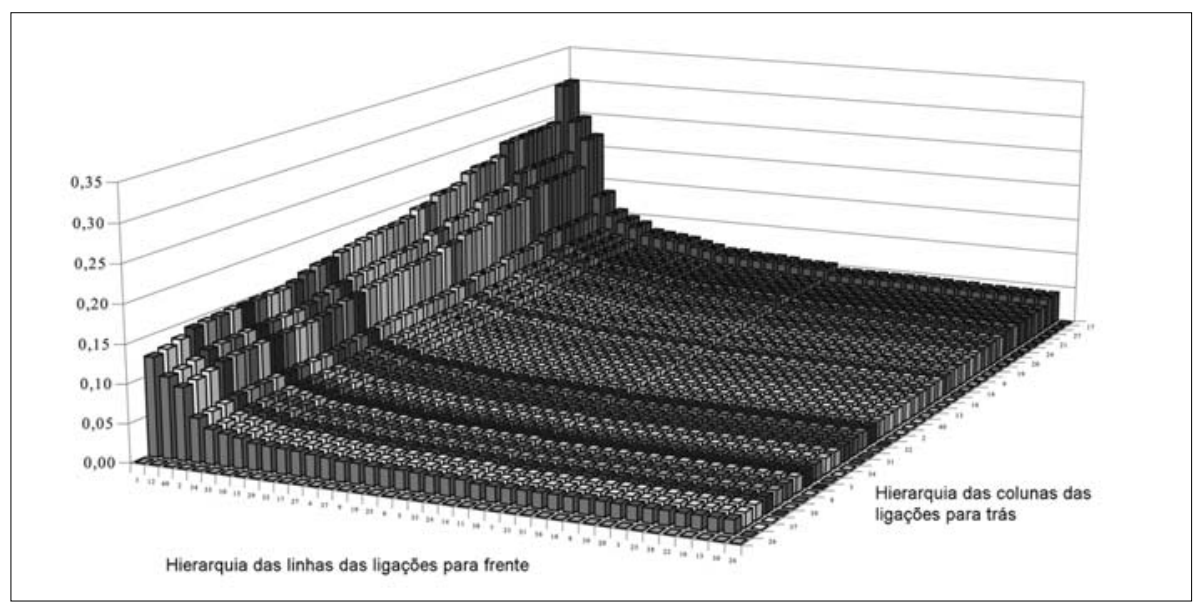

RER, Rio de Janeiro, vol. 42, no 02, p. 243-266, abr/jun 2004 - Impressa em junho 2004 
Em 1985 o setor Química (12) assume a liderança, compondo, com a Indústria do Café Cooperativa (18) e Indústria do Café nãoCooperativa (17), os dois maiores picos da hierarquia, respectivamente. É interessante salientar dois pontos no cenário de 1985 que o diferencia do de 1980: a) o pico da hierarquia em 1985 ocorreu com valores menores do que em 1980; b) do quarto cruzamento em diante, emergiu uma faixa de setores $(2,34,35,10,15,29,32$ e 17) que apresentou crescimento das ligações para frente e para trás em 1985, relativamente a 1980 (Figura 4).

Figura 4 - Topografia da estrutura econômica de 1985 usando a hierarquia do Paraná de 1980.

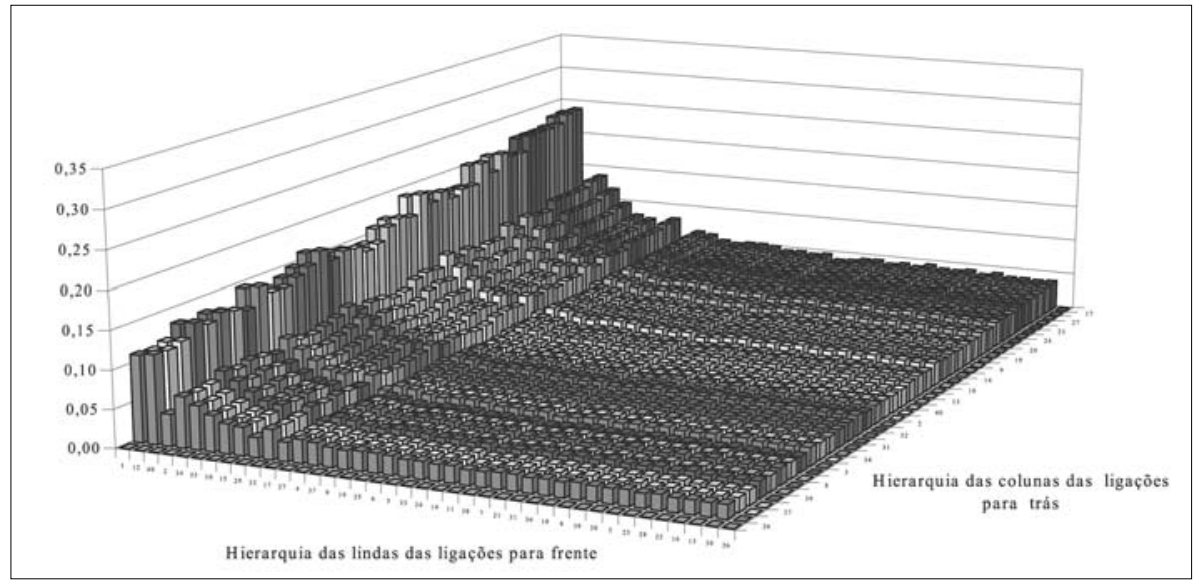

Comparando as Figuras 3 e 4 pode-se perceber que, de 1980 para 1985, a estrutura setorial da economia paranaense mostrou tendência de conformação menos desigual entre os picos, revelando maior diversificação da estrutura produtiva e conseqüente incremento da complexidade econômica.

\section{5 - Considerações finais}

A partir das matrizes de insumo-produto estimadas para o Paraná para os anos de 1980 e 1985 foi possível constatar que somente os setores Celulose, Papel e Gráfica e Indústria Têxtil constituíram setores-chave 
na economia paranaense nesses anos. Entretanto, considerando o conceito menos restrito, outros setores puderam ser assim classificados, dentre eles todos os setores relacionados às cooperativas.

Outra constatação importante refere-se ao fato das cooperativas agropecuárias apresentarem, para os anos estudados, coeficientes técnicos de produção bastante similares aos das empresas não-cooperativas que atuam na agropecuária e na indústria alimentar. Considerando que esses coeficientes refletem a base tecnológica de produção em dado ano, conclui-se que as cooperativas estão acompanhando de perto a evolução tecnológica ocorrida nesses setores, o que confirma a hipótese formulada no estudo.

Uma terceira constatação diz respeito, de um lado, à tendência de perda de importância dos setores alimentares na economia estadual, e de outro, à emergência de outros setores da indústria de transformação, tais como Fabricação de Minerais não Metálicos, Material de Transporte e, em menor grau, Material Elétrico/Eletrônico, delineando tendência futura de maior diversificação industrial.

Considerando que as cooperativas agropecuárias estudadas atuam, basicamente, nos setores alimentares e que estes perderam espaço para outros da indústria de transformação na economia do Estado, pode-se delinear para os setores cooperativo e não-cooperativo paranaenses que atuam na indústria alimentar um cenário de maior concorrência, não somente pela participação na estrutura produtiva do Estado mas, também, pela maior abertura da economia em curso no Brasil.

Embora os resultados deste estudo devam ser entendidos como indicações do comportamento setorial da economia do Paraná nos anos estudados, na medida em que são detectados os setores com maior poder de encadeamento regional para impulsionar o crescimento econômico, os que apresentam os principais elos de ligações dentro da economia, etc., cria-se um conjunto de informações importantes que podem ser trabalhadas para orientar o governo, na definição e adoção de políticas públicas específicas para os setores, e os empresários, no direcionamento de seus investimentos.

Por fim, sugere-se para o futuro estudos que atualizem a presente análise de forma a incorporar informações que permitam confirmar ou não as tendências delineadas no presente artigo. 


\section{6 - Referências Bibliográficas}

BIALOSKORSKI NETO, S.; ZYLBERSZTAJN, D. Cooperativismo - Economia de empresas e estratégias. Perspectiva Econômica, v. 29, n. 84, p. 7-22, 1994. (Série Cooperativismo, n. 35)

BIALOSKORSKI NETO, S. Agribusiness cooperativo: economia, crescimento e estrutura de capital. Piracicaba, 1998. 257p Tese (Doutorado) - Escola Superior de Agricultura "Luiz de Queiroz", Universidade de São Paulo.

CÔTÉ, D.; CARRÉ, G.; BEAULIEU, M. et al. 1995 Profile: agricultural cooperation throughout the world. Montréal: Centre de Gestion des Coopératives/École des Hautes Études Commerciales, 1995. 103 p.

FERGUSON, C. E. Microeconomia. Rio de janeiro: Forense-Universitária, 1982. Cap.8. 610 p.

GONÇALVES, J. S. ; VEGRO, C. L. R. Crise econômica e cooperativismo agrícola: uma discussão sobre os condicionantes das dificuldades financeiras da cooperativa agrícola de Cotia (CAC). Agricultura em São Paulo, v. 41, n. 2. p. 57-87, 1994.

GUILHOTO, J. J. M; SONIS, M.; HEWINGS, G. J. D; MARTINS, E. B. Índices de ligações e setores-chave na economia brasileira: 1959/ 80. Pesquisa e Planejamento Econômico, v. 24, n. 2, p. 287-314, 1994.

HADDAD, P. R.; FERREIRA, C. M. de C.; BOISIER, S. et al. Economia Regional: teoria e métodos de análise. Fortaleza: BNB. ETENE, 1989. 694p. (Estudos Econômicos e Sociais, 36).

HIRSCHMAN, A. O. The strategy of economic development. New Haven: Yale University Press, 1958. 217p.

INSTITUTO PARANAENSE DE DESENVOLVIMENTO ECONÔMICO E 
SOCIAL. Agroindústrias e cooperativas no Paraná. Curitiba: IPARDES, 1985. 55p.

MILLER, R. E.; BLAIR, P. D. Input-output analysis: foundations and extensions. Englewood Cliffs, New Jersey: Prentice-Hall, Inc., 1985. $464 \mathrm{p}$.

ORGANIZAÇÃO DAS COOPERATIVAS BRASILEIRAS (OCB) Números do cooperativismo brasileiro. Brasília: Departamento Técnico e Econômico/Banco de Dados, 1997. 20 p.

ORGANIZAÇÃO E SINDICATO DAS COOPERATIVAS DO PARANÁ (OCEPAR). O Cooperativismo Paranaense. Curitiba - PR, 1997a. 14 p. (Coleção História do Cooperativismo).

ORGANIZAÇÃO E SINDICATO DAS COOPERATIVAS DO PARANÁ (OCEPAR). Projeto de Investimento Agroindustrial das Cooperativas do Paraná. Curitiba - PR, 1997b. 176p. (Apostila).

RASMUSSEN, P. N. Studies in intersectoral relations, Amsterdam: North-Holland, 1956.

RODRIGUES, R. L. Cooperativas agropecuárias e relações intersetoriais na economia paranaense: uma análise de insumo-produto. Piracicaba: 2000. 175p. Tese (Doutorado) - Escola Superior de Agricultura "Luiz de Queiroz”, Universidade de São Paulo.

SONIS, M.; HEWINGS, G. J. D. Error and sensitivity input-output analysis: a new approach. In: MILLER, R. E.; POLENSKE, K. R.; ROSE, A.Z. (Ed.) Frontiers of input-output analysis. New York: Oxford University Press, 1989.

SONIS, M.; HEWINGS, G. J. D. Fields of influence in input-output systems. Urbana: University of Illinois. Regional Economics Applications Laboratory, 1994. (mimeo.)

SONIS, M.; HEWINGS, G. J. D; GUO, J. Input-output multiplier product 
matrix. Urbana: University of Illinois. Regional Economics Applications Laboratory, 1997. (Discussion Paper 94-T-12).

SONIS, M.; HEWINGS, G. J. D. "Economic Landscapes: Multiplier Product Matrix Analysis for Multiregional Input-Output Systems," Hitotsubashi Journal of Economics, v. 40, n. 1, p. 59-74, June 1999.

ZYLBERSZTAJN, D. Organização de cooperativas: desafios e tendências. Revista de Administração, v. 29, n. 3, p. 23-32, jul/set 1994.

Aceito para publicação em março de 2004. 